\title{
Influence of Socio-Cultural Factors on Community Disaster Response During TC Winston: A Case Study of Burenitu Village, Fiji
}

\author{
Akosita Natadra Senimoli ${ }^{*}$, Tammy Tabe ${ }^{1}$, Helene Jacot Des Combes ${ }^{2}$ \\ ${ }^{1}$ Pacific Centre for Environment and Sustainable Development, The University of the South Pacific, Suva, Fiji \\ ${ }^{2}$ National Disaster Management Office, Republic of the Marshall Islands
}

Corresponding Author Email: s95008189@student.usp.ac.fj

https://doi.org/10.18280/ijsse.100305

Received: 1 August 2019

Accepted: 21 April 2020

\section{Keywords:}

attitude, cyclone preparedness, disaster response, disaster risk management, indigenous knowledge, kinship network, mitigation, socio-cultural factors

\begin{abstract}
TC Winston, a Category 5 cyclone made landfall over Viti Levu, Fiji in 2016, causing massive destruction. It caused 44 deaths and destroyed the livelihood of approximately $60 \%$ of Fiji's population. Fatalities and loss would have been reduced if people were proactive. Socio-cultural factors influence community disaster response. This research aims to analyze how indigenous knowledge, kinship networks and attitude influenced community disaster response during TC Winston. The study was done in Burenitu village, in $R a$ province. The research was conducted through a literature review, questionnaire survey, interviews and observations. Procrastination hindered preparedness activities. Indigenous knowledge of cyclone prediction, food preservation and traditional cyclone shelter construction exists among the older generation. It is no longer practised due to reliance on modern weather forecasting, dependency on external relief assistance and reliance on western type of building for evacuation. There is a knowledge gap between the young and old. Loss of indigenous knowledge is inevitable if it is not passed on to the younger generation. Kinship network involved sharing of food and clothes, caring for vulnerable people, evacuation, distributing relief supplies and rehabilitation. In conclusion, the use of indigenous knowledge and kinship networks assisted in community disaster response. Procrastination was a hindrance but was curbed by continuous motivation.
\end{abstract}

\section{INTRODUCTION}

\subsection{Background}

Fiji is prone to tropical cyclones due to its location in the South Pacific tropical cyclone basin. A total of seventy cyclones centres passed within $400 \mathrm{~km}$ of Suva, Fiji's capital, between 1969 and 2010 [1]. Tropical Cyclone Winston, a Category 5 cyclone hit the main islands of Fiji on the 20th of February, 2016. At 6.30 UTC (18.30: local time) the cyclone made landfall over the North-eastern coast of Viti Levu, across the Ra province [2]. This was the first Category 5 cyclone to have directly impacted Fiji and the most intense cyclone to have made landfall in the South Pacific [3]. Maximum average winds reached $233 \mathrm{~km} / \mathrm{h}$ with momentary gusts reaching 306 $\mathrm{km} / \mathrm{h}$ [4]. The tropical cyclone severely devastated the islands in the Lau group, Lomaiviti group, Taveuni, parts of Vanua Levu and Viti Levu.

TC Winston caused 44 fatalities, numerous injuries and impacted $62 \%$ of Fiji's population [4]. Most of the deaths and injuries occurred when people moved from their homes to evacuate to a more secure location during the cyclone, indicating the lack of preparation. This should not have been the case since the Fiji Meteorological Centre started issuing cyclone warnings from the 11th of February through to the 21st of February, 2016.

\subsection{Disaster Risk Management Cycle}

The disaster risk management cycle has four phases: Mitigation, Preparedness, Response and Rehabilitation. A simple representation of the Disaster Risk Management Cycle is shown in Figure 1.

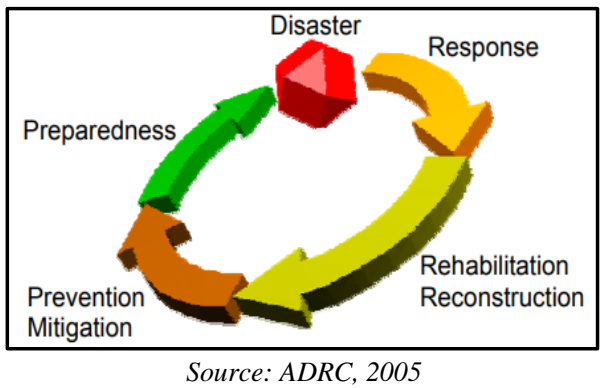

Figure 1. Disaster risk management cycle

Mitigation is a pre-disaster phase where efforts are made to increase resilience. Mitigation activities may include the construction of cyclone certified homes. Preparedness is also a pre-disaster phase that involves all activities carried out to fully prepare for an emergency. Preparedness is a state of readiness to respond if a disaster strike. Examples of preparedness activities include installation of early warning systems, stockpiling of food, water and other needed materials. The Response phase consists of all the efforts and activities 
occurring during and after a disaster. Response activities include rescue, attending to casualties and building temporary shelters. Immediately after a disaster, rehabilitation and reconstruction activities begin. Rehabilitation and reconstruction focus on restoring people's lives to normalcy as soon as possible. Activities include livelihood support and building disaster-resistant buildings. The four phases are interconnected and overlap at all times meaning several phases can occur simultaneously.

\subsection{The influence of socio-cultural factors}

Studies have shown that socio-cultural parameters influence people's response to disasters [5]. Traditions, belief system, and practices in a society influence people's values, attitude, feelings, and behaviour. Socio-cultural factors influence people's response in a disaster. There are a number of researches that have studied human behaviour during a disaster. Human behaviour can either be conducive or obstructive to DRM initiatives which societies need to know [6]. The behaviour of individuals before, during and after a disaster can greatly affect the impact and the recovery time [7]. Along this line, international organizations and research scholarships have emphasized that having a better understanding of human behaviour can improve the effectiveness of disaster risk management [5]. Lessons learnt from people's responses to past disasters can be incorporated into effective DRM policies [5].

People's behaviour during a disaster is influenced by environmental, economic, political and socio-cultural factors. Socio-cultural attitudes influences a person's readiness to listen, follow, modify or reject safety measures offered by external sources [8]. A number of DRM researches focussed on the influence of socio-cultural factors on mitigation [5]. Understanding the influences of socio-cultural factors on disaster risk can help emergency managers to tailor policies for effective practices [5]. Therefore there is a need to study the socio-cultural settings of the Fijian communities, with a focus on how these settings influence disaster preparedness and response, particularly in communities that were directly affected during cyclone Winston.

The Ra province was one of the areas in Fiji that were badly hit by TC Winston. This study focuses on the socio-cultural factors that affected disaster response in Burenitu village, located in the Ra province. Evaluation and understanding of how people behaved during the disaster response period should allow stakeholders to make improvements on mitigation, preparedness and response initiatives in rural indigenous Fijian communities.

The location of Burenitu village in relation to the path taken by TC Winston is shown in Figure 2.

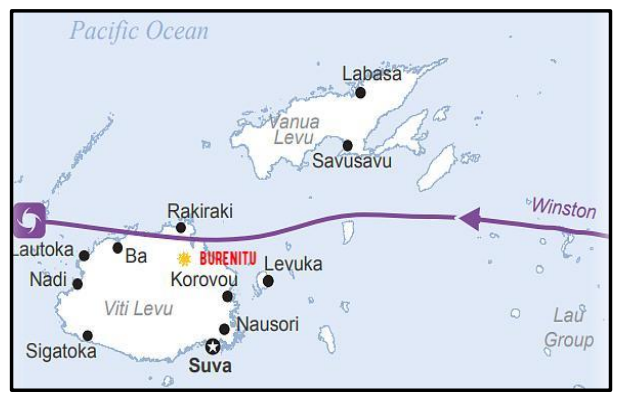

Figure 2. Map showing the location of Burenitu village in relation to the path taken by TC Winston

\subsection{Burenitu village}

Burenitu village is located in the district of Nalawa, $\mathrm{Ra}$ province. It is approximately 40 kilometres from Rakiraki town and 2 kilometres from its road junction along the Kings Road. The village is accessible by road and regular public transport from Rakiraki, Suva and Lautoka continues throughout the day via the Kings Road. The village consists of 65 households with a total population of 294 living within the village boundary. Families living on their farms and settlements as well as those who live away from the village for study, work or religious reasons were not included in the study. For administrative convenience, the village is divided into six clans or mataqali namely Waimaro, Wai, Navunidoi, Lau, Natauia and Nakorotubu. Different mataqali occupy different sections of the village. Members of extended families build their houses next to each other.

\subsubsection{Governance}

Indigenous Fijian (i-Taukei) communities are organized into a hierarchical system of governance based on communal ownership [9, 10]. Governance structure at the village level is strong "as people have strong kinship ties and family units with strong beliefs and trusts" [11]. These bonds and relationships maintain unity, cooperation and submission to authority in the community. Leadership is vested on the traditional leader or chief. In a fully traditional village, ' $e d u a$ ga na domo e rogoci' which is translated as, 'only one voice is heard'. This means that only the chief's voice should be heard as he is the only one that has the 'final say' in decision making for the whole village. All administrative duties are carried out by the Turaga ni Koro (village headman). The post of the Turaga ni Koro was created during the colonial era (British rule in Fiji) to be the liaison officer between the colonial government and the village. Today the role remains. The Turaga ni Koro is still the main point of contact between the government departments and the village.

Each clan in a village has age-old roles and responsibilities. Over time, the members of these different clans have become quite skilful in their trade. These traditional roles and responsibilities ensure "division of labour" and maintain cooperation, peace and harmony in the village.

The village has a village council and is headed by the village chief. This council includes all the adults in the village. Eight committees work under the village council: health, electricity, education, youth, development, environment, water and women.

\subsubsection{Disaster Risk Management in Burenitu}

There is no committee that is solely responsible for Disaster Risk Management and the village does not have a disaster plan. In times of disaster, the Turaga ni Koro oversees all the preparedness, response, recovery and rehabilitation activities taking place and villagers volunteer to help. There are generally three evacuation centres in the village that includes the Methodist church, the village hall and the Assemblies of God church. There are also a number of houses that are usually used for evacuation.

\section{METHODOLOGY}

The research was conducted through literature review, questionnaire survey, interviews, talanoa sessions and 
observation. The field work was done in Burenitu village, an indigenous Fijian community. This community was chosen as a representation of the major ethnic group in $\mathrm{Ra}$, constituting $66.5 \%$ of the total population [12]. Secondly, Burenitu was similar to all other communities in Ra which succumbed to the destruction caused by TC Winston. The cyclone initially made landfall across Vitilevu Bay, in Ra, making the province one of the areas in Fiji that were declared 'ground zero'.

The data collection period in the field was carried out for one month from the $4^{\text {th }}$ of September, 2017 to the $8^{\text {th }}$ of October, 2017. The fieldwork required staying in the community throughout the study and taking part in most, if not all, of village activities that concurred. Field notes were recorded daily.

Multiple data gathering tools were employed to capture various dimensions of the phenomenon. Triangulation was used to increase the validity and reliability of the data collected. Triangulation was done in two ways such as the use of multiple data collection tools and multiple data sources. For ethical consideration, full disclosure, confidentiality, voluntary participation and cultural sensitivity were considered.

There was a set of interview questions and two sets of questionnaires given out. Two individuals were interviewed: the chief (Ratu ni Bure), and the Village Headman (Turaga ni Koro). The first set of questionnaires was given to all households and aimed at collecting information about the population, preparedness and response activities. The second questionnaire targeted three major groups; the youth, the middle-aged and the senior members. This was done to get a rich diversity of viewpoints from the population. For this second questionnaire, stratified random sampling was used. The population in each community was divided into the three sub-groups or strata as mentioned above. Four individuals (two males and two females) were picked randomly from each stratum. In addition, there were four talanoa sessions conducted where the participants possessing adequate traditional knowledge of dealing with disasters were chosen. Talanoa is an indigenous data gathering method for naturalistic inquiry used in the Pacific [13]. All the talanoa sessions were informal. Audio recording and note-taking were used to collect the information. The talanoa sessions were conducted by the main researcher who guided the discussions to cover all the relevant issues.

Before data analysis was carried out, all interview recordings were transcribed and translated into English. Observation and ethnographic data were also compiled. All data collected was analyzed manually by the Constant Comparative Method using Open Coding [14]. The transcripts were read line by line. Concepts and themes emerging were given codes. Codes were compared and placed in categories. After the whole transcript was coded, similarities between the codes were compared and the codes were modified and reduced to include a wider range. Using the Constant Comparative Method, related categories were merged together to form themes. These themes became the main concepts discussed in the findings of this study.

\section{DISASTER PREPAREDNESS AND RESPONSE}

Disaster preparedness and response are two vital phases of the Disaster Risk Management cycle. If more emphasis is placed on disaster preparedness and response, fatalities, injuries and devastation caused by disasters can be greatly reduced. For example, Cyclone Phailin (Category 5) caused a US $\$ 4.5$ billion damages but caused only 22 deaths in the state of Orissa, India due to the timely evacuation of the people. In contrast, Typhoon Haiyan (Category 5) caused 6000 deaths due to the lack of early evacuation [15].

\subsection{Cyclone preparedness and response in Burenitu village}

TC Winston hit the village on Saturday, the $20^{\text {th }}$ of February, 2016 from approximately 5 to $7 \mathrm{pm}$. The villagers were not fully prepared for a cyclone of this magnitude. Information of the approaching cyclone was heard by word of mouth and over the radio. $45 \%$ of the survey respondents heard the cyclone warning a few days earlier while the rest heard about it on the same day. $56 \%$ of the respondents did not make any prior preparations for TC Winston although they had heard the warning. While a few people started putting up cyclone shutters, preparing food and moving to the evacuation centre, a large number of people continued with their business as usual. Several villagers went to sell their produce at the market in Rakiraki and Lautoka, a group of young men went to participate in a rugby tournament and there was a birthday party held on that very afternoon. These activities were not called off. As a result, people were stranded in their various locations at the height of TC Winston.

Actions changed drastically when people realized the seriousness of the situation. As the cyclone intensified, people started moving to safe houses. The Methodist church, several houses and the village halls were used as evacuation centres. Movement of evacuees occurred between strong gusts to prevent injuries from flying debris. There was no death in the village itself but there were some serious injuries. As the cyclone moved away, evacuation of people whose homes have been destroyed continued. Some women were hiding under the floorboards of their destroyed wooden houses. A number of families resorted to hiding in the concrete sections of their homes which is the toilet and bathroom. For most people, all their clothes were wet and they remained with those wet clothes until the next day. Response efforts continued throughout the night by addressing the immediate needs such as moving people to secure locations. The nurses in the village were instrumental in providing medical attention to the sick and the injured during this emergency period. Clearing of debris, cleaning up and washing started on the next day which was Sunday. On Monday, male members of the village got together and started building temporary shelters to provide for those that have lost their homes. Rehabilitation and recovery continued for several months after the cyclone.

\section{FINDINGS}

The three socio-cultural factors that are considered in this study are: indigenous knowledge, kinship network and attitude.

\subsection{Indigenous knowledge}

Traditional knowledge or "indigenous knowledge refers to the methods and practices developed by a group of people from an advanced understanding of the local environment, which has formed over numerous generations of habitation" [16, p.vii]. Constantly over generations, new knowledge is integrated into the existing one. This knowledge is usually passed down orally or in any other traditional forms and 
perfected over generations. There are numerous success stories where traditional knowledge has preserved buildings, saved lives or ensured food security in disasters. For instance, houses built with the Taq (timber laced masonry) and DhajjiDewari (timber frame with an infilled wall) building system were able to survive the 2005 Kashmir earthquake [16] better than buildings using other designs. Another striking example is the use of a traditional cyclone shelter, nimaleten in Tanna, Vanuatu that enabled a number of people to survive the wrath of TC Pam in 2015 [17].

Using traditional early warning signs, the Simeulueans living along the coast of Sumatra, Indonesia and the Mokens of Thailand were able to escape the Indian Ocean tsunami of 2004 [16]. On islands with limited telecommunication and internet access, traditional signs can be very useful to help people prepare for approaching disasters. Responding to traditional warning signs together with information learnt from a video helped the indigenous people of Baie Martelli, Vanuatu escape to higher grounds during the 1999 tsunami [18].

There are eight items gathered from the study which are considered relevant for Mitigation, Preparedness and Response.

\section{(i) Traditional warning signs of an approaching cyclone}

All respondents know at least one traditional sign foretelling a cyclone. Traditional signs can be divided into two types: the signs that can be seen a few months or weeks before the cyclone and those that occur immediately before the cyclone. Weeks before the cyclone, traditional signs include hornets nesting close to the ground, more than one breadfruit on one stalk, extremely hot weather, drying up of nearby ponds. Immediately before the cyclone, traditional warning signs include seabirds flying landward, dogs hiding and clouds moving very fast. Several respondents mentioned seeing several of these signs but all of them left the issue on the back burner. A few people mentioned seeing the fast-moving clouds and seabird flying landward shortly before the cyclone hit but by that time they had already known about the approaching cyclone from cyclone warnings aired over the radio.

\section{(ii) Traditional cyclone shelter ('aqa'aqaqele)}

Four respondents all above 50 years of age, mentioned a traditional cyclone shelter called the 'aqa'aqaqele. The triangular prism-shaped structure serves as a roof and wall. The structure of the 'aqa'aqaqele is similar to the roof of a 'bure' but very small. The posts are fixed securely deep into the ground and pandanus leaves, coconut leaves or reeds are used to thatch the roof-wall. This shelter was used by elders in the community as a cyclone shelter. These traditional cyclone shelters are no longer used now. Only the older generation in the community reported seeing these types of shelters in the past.

The structure of the 'aqa'aqaqele, is similar to the cyclone shelter called nimaleten from Tanna, Vanuatu. Figure 3 shows a nimaleten that is under construction. The nimaleten is constructed from wood, creepers, palm and pandanus leaves. The slope of the roof reaches the ground making it difficult for the wind to blow the roof off [17]. The wind slides over the roof "rather than through or under it" [17]. There were five deaths on Tanna during TC Pam in 2015. Three of those casualties died when the walls and roof of a concrete church fell on them. People who sought shelter in traditional cyclone shelters escaped the disaster unharmed [17].

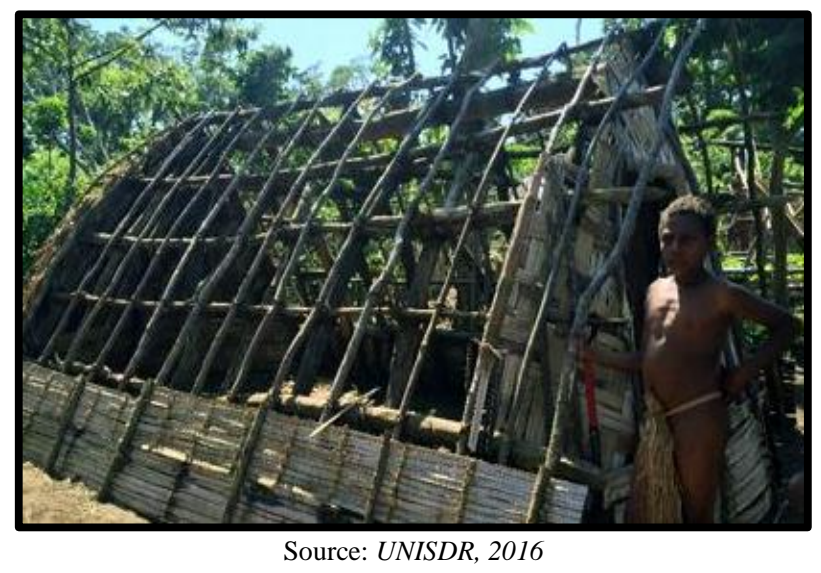

Figure 3. A nimaleten that is still under construction in Tanna, Vanuatu

\section{The bure (traditional Fijian house)}

The bure is a safe building during a cyclone. The roof seldom blows away due to its heavy weight but collapses to the ground preventing injuries. The fallen roof can serve as a good shelter just similar to the 'aqa'aqaqele. Unfortunately, there is no bure left in Burenitu village.

The bure can be constructed as an initiative for selfrecovery by an affected community because the materials for its construction are available locally. Due to problems of transportation, shortage of building materials from the suppliers similar to what was experienced in Ra after TC Winston; the bure can be constructed as a solution to housing. The disadvantage of bure construction is that it is labour intensive and takes time to complete. A bure cannot be built straight after a cyclone, because it needs natural materials like reeds, timber and other materials which will not be available after a disastrous cyclone.

\section{(iii) Underground pit for fermenting cassava (Mo'i ni tavioka)}

Cassava (Manihot esculanta) rots quickly after the plants are shaken in a cyclone. To preserve large amounts of mature cassava after a cyclone, subterranean fermentation is done. Fermentation is a common method of food preservation [19]. Subterranean cassava fermentation (mo'i ni tavioka) is done to ensure food security months after the cyclone.

A pit of approximately 1-2 metres in diameter and 0.5-2 metres in depth is dug in the ground. Pits are normally circular in shape and should be big enough to fit all the cassava. Stones are placed at the bottom of the pit to make it firm. Banana (Musa acuminata) and turmeric (Curcuma longa) leaves are used to adequately cover the bottom and sides of the pit to prevent the cassava from getting into contact with the soil. Cassava is peeled, washed and then placed in the pit. The cassava is then covered again with more banana and tumeric leaves. The pit is then buried with enough soil to form an airtight cover. Stones can be placed at the top to prevent pigs from digging up the cassava. Cassava can be buried for several months or even years. After several months in the soil, cassava becomes soft. Fermented cassava can be dug up when it is needed and then the pit is reburied for future use. The fermented cassava is further mashed and wrapped in banana or breadfruit leaves and baked in the lovo (underground stone oven). Baked cassava can be kept and eaten over a period of several days. 
Subterranean fermentation of cassava is not very common and there is no record of the process being carried out in other parts of Fiji or the Pacific. A more common method of cassava fermentation in Fiji involves soaking the cassava in water for several weeks until they become soft. The soft cassava is then removed from the water, mashed and dried in the sun. Sugar and coconut cream are added then the mixture is wrapped in vasili (Cordyline fruticose) leaves and steamed.

Subterranean fermentation of cassava is similar to the fermentation of mature breadfruit, a tradition of Micronesia [19]. The preparation and fermentation method of breadfruit varies throughout Micronesia [19]. Breadfruit is seasonal food Fermentation is done to ensure food security after cyclones, droughts and breadfruit off-season. Fermentation of breadfruit is done during the breadfruit season. On Afalik atoll, in the Federated States of Micronesia (FSM), the process involves the removal of the breadfruit skin either by scraping or peeling. The breadfruit is beaten inside a sack in the sea. The breadfruit is then soaked overnight. On the following day, the soaked breadfruit mass is taken out of the sack and left on coconut leaf baskets to drain and ferment for five days. The breadfruit is then placed in pits already lined with dry breadfruit and banana leaves. More breadfruit and banana leaves are used to cover the breadfruit mass. The breadfruit pits can be kept for several years. The fermented breadfruit is taken out and baked when it is needed for consumption [19]. On the island of Pohnpei, the longer the breadfruit is kept in fermentation pit, the more prestigious it becomes [20].

In Burenitu, the mo' $i$ ni tavioka has not been used since the mid-twentieth century. According to the villagers, the main reason is the availability of other food options such as rice and flour. Nowadays, food relief arrives almost immediately after the cyclone, making people more reliant on outside help rather than ensuring their food security. Another reason is that the process of preparing fermented cassava in this way is a strenuous activity as well as time- consuming.

\section{(iv) Swamp taro or Via sori and Via dina, (Cyrtosperma merkusii)}

Cyrtospera merkusii is used as kakana dina or staple food after cyclones. In this locality, swamp taro is not a cultivated crop. It is only eaten during emergency situations when all crops are destroyed after a disaster. The swamp taro is not eaten because of the itchy sensation it leaves on the tongue. It has to be cooked for a very long time to neutralize this itchy sensation. The swamp taro is peeled and baked and can be kept for several days.

\section{(v) Planting crops during the cyclone season}

Planting during the cyclone season gives crops a head start. The crops will still be small during the cyclone season, lessening damage in the occurrence of a cyclone but ensuring food security more quickly after a disaster. This method of planting is shared by one of the successful farmers in this village. It was not discussed by any other respondent but it is included in this discussion due to the validity of his explanation.

\section{(vi) Resilient crops}

Planting cyclone resilient crops like yam (Genus: Dioscorea) and kumala or sweet potato (Ipomoea batatas).

Yams or uvi (Genus: Dioscorea):
$>$ Yams are resilient to the destructive effects of cyclones. According to a yam farmer, he was still able to sell yams for export after TC Winston. That meant his crops were not destroyed after the cyclone. His family was also eating the yams until the cassava that was planted after the cyclone matured. Yams can also be kept for years if they are kept dry.

$>$ There are several varieties of yams. In villages, men keep mounds of tivoli or wild yam, that remain in the ground for a long time. Several varieties of tivoli can be harvested from time to time by just removing the amount that is needed to be harvested and burying the remaining tivoli in the ground. This is a common practice in Fijian villages.

$>$ Sweet potato or kumala (Ipomoea batatas). Kumala matures after about three months. Many people said that is the first crop that they plant after cyclone disasters because of its quick maturation time. This is a common practice in the village.

\subsection{Kinship network (veiwekani)}

I-Taukei kinship network is extensive and portrays a collectivistic nature. This network is an integral part of the indigenous Fijian way of life. In a village, everybody is related by blood and by marriage. Brothers, sisters, father and mother relationship are not only limited to the nuclear family. A cousin is referred to as a brother or a sister. The close bond between siblings within a nuclear family extends out into the extended family, the village, district and province. Megan Lee [21] wrote that the indigenous Fijian society allows little room for independence and personal autonomy. Individualism is not seen in a traditional Fijian setting.

\subsubsection{Sharing and caring}

Sharing and caring for each other is a way of life in an indigenous Fijian community that positively influences disaster response. Blood relatives care for one another and sharing occurs freely. Families who have been left homeless stayed with their relatives for weeks until their homes were rebuilt. The network of veiwekani mentioned above was very useful during the cyclone. Once the roads were cleared, the villagers immediately contacted their relatives living in other parts of Fiji or overseas. Help came immediately from relatives and also from concerned citizens of Fiji.

\subsubsection{Communal work (solesolevaki)}

In an indigenous Fijian village, work is usually carried out communally. When people work as a team, the work becomes lighter and more can be achieved in a shorter time as compared to carrying out the same task individually. Solesolevaki positively influences community disaster response because more work can be done in a short period of time and the needs of the vulnerable people can also be catered for. Men belonging to Mataqali Nakorotubu, got together straight after the cyclone and started clearing the debris from around their compounds. They built shelters using debris tins for families that lost their homes. This allowed the families that were housed in the village church and other evacuation centres to move back into their houses quickly before permanent buildings can be built. While these activities were being done, the women and children helped in the cooking and washing of the clothes that were wet from the cyclone. 


\subsection{Attitude}

\subsubsection{Procrastination (Mosimosi vaka-Bure)}

Mosimosi vaka-Bure is normally referred to the nature of the kai Bure's approach to doing things. Kai Bure in this sense refers to the natives of Burenitu. The word mosimosi in the Burenitu dialect means a plan of action. The expression refers to way they delay their action in carrying out certain tasks and responsibilities. Basically this expression is a special name given to procrastination. People tend to drag their time in carrying out activities. Mosimosi vaka-Bure is a hindrance to disaster preparedness and response since people tend to take their time in carrying out certain chores. This can be addressed if people are made aware of the urgency of carrying out certain activities and they need to be encouraged to meet the deadlines of assigned tasks.

\subsubsection{Prior experience}

Preparedness for disasters is influenced by prior experience. "Direct experience can be a strong motivator for preparedness" [22, p.1]. Past studies have shown that prior experience of a disaster changes people's attitude towards preparedness. People that have experienced a disaster perceive the risk better hence are more prepared than those with no prior experience [23]. Furthermore, the intensity of the natural disaster experience is critical to the perception of the risk and the level of preparedness $[23,24]$. Another study found that individualism-collectivism orientation influences an individual's perception of preparedness [24]. None of the respondents mentioned experiencing any other strong cyclones in the recent past. The middle-aged group mentioned Cyclone Bebe, a strong cyclone that occurred in 1972 while the much older generation mentioned another cyclone that occurred in 1952. For those that mentioned other cyclones, TC Winston was the most destructive.

The lack of prior experience can be a contributing factor as to why people took the cyclone warning lightly thinking that the cyclone not come their way. Having gone through the ordeal of TC Winston, everybody that was interviewed and those who answered the questionnaires mentioned their attitude will be different when another cyclone comes. There are lessons learnt from their experiences include following the instructions given in the cyclone warning, strengthening spiritual life, building stronger houses and to be proactive.

\section{DISCUSSION}

The findings from the survey in Burenitu showed links to how indigenous knowledge, kinship network and attitude influence community disaster response. The following discussion further explains the connections between these socio-cultural factors and disaster mitigation, preparedness and response.

\subsection{Indigenous knowledge}

The community possesses adequate indigenous knowledge of how to deal with disasters. Indigenous knowledge has been perfected over generations and has helped people survive the devastation of previous disasters. Early warnings of approaching disastrous events are shown by the signs they see in the surrounding. Heavy fruiting in trees, extremely hot weather and hornets nesting very close to the ground are some of these signs give them warning to reinforce their houses using vines and bamboos. They harvest crops that can keep for long and cut down branches of cassava plants to reduce shaking of the branches during the cyclone. Cyclone shelters ('aqa'aqaqele) are built in preparation for the cyclone season. After a cyclone, they either dig pits to bury cassava that is not damaged, or peel them and ferment them in leaf-lined pits called the mo' $i$ ni tavioka. The pits of cassava can supply food for the family's meals in the following months. Other food sources include swamp taro and wild yams. In addition to rehabilitation work, men start planting food crops such as sweet potato and cassava to meet future food needs.

Practices mentioned above are not followed nowadays due to various reasons. A lot of help is now received immediately after a cyclone hit. Cyclone relief comes in the form of food, water, temporary housing and other items that satisfy basic human needs. People started relying on this form of cyclone relief. As a result, indigenous knowledge of disaster mitigation, preparedness and response slowly die out. Another reason is the increased reliance on modern weather forecasting and western type building for evacuation. Now, most of the indigenous knowledge is only possessed by the older generation who have practised them when they were young. It can be seen that there is a generational knowledge gap between the young and old. Indigenous knowledge can be lost if not passed on to the younger generation. The knowledge of building traditional cyclone shelters, methods of food preservation, methods of planting crops for cyclone resilience are now only possessed by the older generation. Since several practices are not in use now, the younger generation is ignorant about them. Elders are responsible for transferring their knowledge to their children in order to bridge this knowledge gap. The issue is also calling for the involvement of the institutions that manage I-Taukei Affairs to find ways of preserving this knowledge. Traditional knowledge will be lost if nothing is done to address it.

More importantly, for the context of this study, retaining indigenous knowledge will surely help fortify initiatives for disaster risk reduction in Fiji which stakeholders need to consider. Preserving indigenous knowledge is critical to making indigenous Fijian populations become more resilient to future cyclones. Indigenous people and relevant stakeholders need to aware of the fact that this knowledge is precious since it has been refined and perfected over many generations of responding to disasters.

\subsection{Kinship network (veiwekani)}

Kinship is a strong network that is very influential in the rapid progress of disaster response and recovery. Indigenous Fijians value their blood ties. During the disaster, everyone worked together in evacuating, responding to the immediate needs of their relatives. Families and clans worked together doing solesolevaki or communal work that involved the rebuilding of temporary houses, the distribution of relief supplies, cleaning up, washing and cooking. There was sharing of food, clothing and other necessities. Relatives living in urban areas and those living abroad lent a helping hand through financial means and in kind. There was a lot of sharing and caring amongst the people. The share and care mentality ensures no one is left behind during disaster response. Everybody will look out for his brother or sister, neighbour or friend. 


\subsection{Attitude}

The lack of preparations for any disaster is common which may be influenced by the view that the disaster would not severely affect them. This study found that $56 \%$ of the people did not prepare for TC Winston. Individuals show different attitudes towards disaster response. Procrastination and lack of prior experience have shown to affect disaster mitigation, preparedness and response. Procrastination referred to in Burenitu as mosimosi vaka-Bure hindered preparedness activities. People procrastinated and it came at a price. Many people have heard about the cyclone warning but delayed their preparations. They carried out their daily routines instead of responding to the cyclone warning. Taking proactive measures could have reduced damages and destructions. Making prior preparations such as preparing food, water, moving livestock to secure places, reinforcing houses and moving to evacuation centres could have reduced damages and injuries encountered. The lack of prior experience also influenced their attitude.

\section{CONCLUSION}

The results from the study have shown the influence of a number of sociocultural factors on disaster response. The study community was found to possess a wealth of indigenous knowledge that can help reduce disaster risk, minimize damages and fatalities in a cyclone. A problem arising is that indigenous knowledge is not widely practised and only possessed by the elders. Indigenous knowledge is on the verge of being lost if it is not passed on to the next generation. Kinship network, on the other hand, is a pillar of strength for community disaster reduction actions. There is a strong bond between blood relatives where solesolevaki, sharing and caring help people to work together to respond better during cyclone emergencies. Lastly, procrastination and lack of prior experience can hinder disaster response efforts while this can be curbed by constant motivation and awareness.

\section{ACKNOWLEDGMENT}

Sincere gratitude goes to the 'Vanua o Bure, Na Turaga na Ratu ni Bure', everyone from Burenitu that have contributed to the field survey and those that have taken time to answer further queries later. Heartfelt appreciation also goes to the USP Research Office for providing the grant for this study.

\section{REFERENCES}

[1] PCCSP. (2013). Current and Future Climate of the Fiji Islands. Suva: Pacific Climate Change Science Program, p. 8.

[2] UNITAR-UNOSAT. (2016). Tropical Cyclone Winston UNOSAT Damage Assessment Activities in Viti Levu Island, Fiji 09 March 2016 - Report. Retrieved from Geneva, Switzerland.

[3] Terry, J.P., Lau, A.Y.A. (2018). Magnitudes of nearshore waves generated by tropical cyclone Winston, the strongest landfalling cyclone in South Pacific records. Unprecedented or unremarkable? Sedimentary Geology, 364:

276-285.
[4] Esler, S. (2016). Fiji Post Disaster Needs Assessment: Tropical Cyclone Winston, February 29, 2016. In G. o. Fiji (Ed.). Suva: Government of Fiji.

[5] Kasdan, D.O. (2016). Considering socio-cultural factors of disaster risk management. Disaster Prevention and Management, 25(4): 464-477. https://doi.org/10.1108/Dpm-03-2016-0055

[6] Neumayer, E., Plümper, T. (2007). The gendered nature of natural disasters: The impact of catastrophic events on the gender gap in life expectancy, 1981-2002. Annals of the Association of American Geographers, 97(3): 551566. https://doi.org/10.1111/j.1467-8306.2007.00563.x

[7] Aerts, J.C.J.H., Botzen, W.J., Clarke, K.C., Cutter, S.L., Hall, J.W., Merz, B., Kunreuther, H. (2018). Integrating human behaviour dynamics into flood disaster risk assessment. Natura Climate Change, 8(3): 193-199. https://doi.org/10.1038/s41558-018-0085-1

[8] ICIMOD. (2009). Socio-cultural engagement and sentivity in Disaster Risk Reduction. Latipul, Nepal: ICIMOD Publication Unit.

[9] Yabaki, Y. (2006). Women's Life in a Fijian village. (Doctor of education), University of Canberra, Canberra, Australia.

[10] Sloan, J., Chand, K. (2015). A review of near shore fisheries law \& governance in Fiji. David and Lucille Packard Foundation, p. 30.

[11] Kitolelei, J.N.S.T., Tori, K.K. (2014). Formalization of traditional rules and governance in Fiji coastal communities: A case study of Veivatuloa village. Evolutionary and Institutional Economics Review, 11(1): 14. https://doi.org/10.14441/eier.110104

[12] FBS. (2017). Population Census

[13] Nabobo-Baba, U. (2008). Decolonizing framings in Pacific research: Indigenous Fijian Vanua research framework as an organic response. AlterNative: An International Journal of Indigenous Peoples, 4(2): 140154. https://doi.org/10.1177/117718010800400210

[14] DePoy, E., Gitlin, L.N. (2016). Chapter 21 - Analysis in Naturalistic Inquiry Introduction to Research. Fifth Edition. St. Louis: Mosby, pp. 270-281.

[15] Walch, C. (2018). Evacuation ahead of natural disasters: Evidence from cyclone Phailin in India and typhoon Haiyan in the Philippines. Geo-Geography and Environment, $\quad 5(1)$ : https://doi.org/10.1002/geo2.51

[16] UNISDR. (2008). Indigenous Knowledge for Disaster Risk Reduction: Good Practices and Lessons Learned from Experiences in the Asia-Pacifi c Region. In Rajib Shaw, Noralene Uy, \& J. Baumwoll (Eds.), (July, 2008 ed., pp. 97). Bangkok.

[17] Walshe, R.A., Nunn, P.D. (2012). Integration of indigenous knowledge and disaster risk reduction: A case study from Baie Martelli, Pentecost Island, Vanuatu. International Journal of Disaster Risk Science, 3(4): 185194. https://doi.org/10.1007/s13753-012-0019-x

[18] Timoko, M. (2015). Local knowledge saves lives in Vanuatu. Vanuatu: UNISDR.

[19] Atchely, J., Cox, P.A. (1985). Breadfruit fermentation in Micronesia. Economic Botany, 39(3): 326-335. https://doi.org/10.1007/BF02858803

[20] Levin, M.J. (2017). Breadfruit fermentation in Pohnpei, Micronesia: Site formation, archaeological visibility, and interpretive strategies. The Journal of Island and Coastal Archaeology, 13(1):

109-131. 
https://doi.org/10.1080/15564894.2017.1382618

[21] Lee, M. (2000). Life in a Fijian Village: The Struggle of Self and Community.

[22] Becker, J.S., Paton, D., Johnston, D.M., Ronan, KR., McClure, J. (2017). The role of prior experience in informing and motivating earthquake preparedness. International Journal of Disaster Risk Reduction, 22(Supplement C): https://doi.org/10.1016/j.ijdrr.2017.03.006

[23] Becker, J.S., Paton, D., Johnston, D.M., Ronan, K.R.,
McClure, J. (2017). The role of prior experience in informing and motivating earthquake preparedness. International Journal of Disaster Risk Reduction, 22(Supplement C): 179-193. https://doi.org/10.1016/j.ijdrr.2017.03.006

[24] Sandanam, A., Diedrich, A., Gurney, G.G., Richardson, T.D. (2018). Perceptions of cyclone preparedness: Assessing the role of individual adaptive capacity and social capital in the wet tropics, Australia. Sustainability, 10(4). https://doi.org/10.3390/su10041165 